\title{
Definition of postoperative bleeding in children undergoing cardiac surgery with cardiopulmonary bypass: One size doesn't fit all
}

\author{
David Faraoni, MD, PhD, FCCP, FAHA
}

\author{
From the Division of Cardiac Anesthesia, Department of Anesthesia and Pain Medicine, Hospital for Sick Chil- \\ dren, University of Toronto, Toronto, Ontario, Canada. \\ Disclosures: Author has nothing to disclose with regard to commercial support. \\ Received for publication Dec 19, 2017; accepted for publication Jan 15, 2018; available ahead of print Feb 13, \\ 2018. \\ Address for reprints: David Faraoni, MD, PhD, FCCP, FAHA, Division of Cardiac Anesthesia, Department of \\ Anesthesia and Pain Medicine, Hospital for Sick Children, 555 University Ave, Toronto, Ontario M5G 1X8, \\ Canada (E-mail: david.faraoni@mail.utoronto.ca). \\ J Thorac Cardiovasc Surg 2018;155:2125-6 \\ $0022-5223 / \$ 36.00$ \\ Copyright (C) 2018 by The American Association for Thoracic Surgery \\ https://doi.org/10.1016/j.jtcvs.2018.01.017
}

Neonates and infants undergoing cardiac surgery with cardiopulmonary bypass are at high risk for bleeding and frequently require the transfusion of large volumes of blood products. ${ }^{1}$ Over the past decades, several authors have tried to understand the mechanisms leading to abnormal bleeding, as well as to identify predictors for excessive bleeding in neonates and children undergoing cardiac surgery with cardiopulmonary bypass. ${ }^{2}$ Although some important risk factors have been identified (Figure 1), significant inter-study/center variability in terms of management strategy, perioperative bleeding, transfusion, and outcome has been highlighted. ${ }^{3}$ The heterogeneity between centers make the development of an "universal" definition of excessive bleeding extremely challenging.

In the current issue of the Journal, Bercovitz and colleagues ${ }^{4}$ report the results of a retrospective study that aimed to derive and validate a definition of postoperative bleeding that can be applied to neonates and infants undergoing cardiac surgery. ${ }^{4}$ The study is an important piece because it highlights the large inter-center/study heterogeneity in terms of postoperative bleeding and the need for center-based definition of excessive bleeding. The authors hypothesized that the absence of a standardized definition of postoperative bleeding is a barrier to improving bleeding-related outcomes and that the development of a definition of bleeding would have the potential to improve clinical research and patient care with respect to diagnosis, prevention, and treatment of bleeding. The authors performed a systematic review of the literature, and analyzed the definitions of excessive postoperative bleeding used in each published study. A regression model tree was used to determine chest tube output volumes that were associated with red blood cell transfusions and surgical reexploration for bleeding in the first 24 hours after intensive care unit admission. Excessive bleeding was defined as $7 \mathrm{~mL} / \mathrm{kg} / \mathrm{h}$ or more for 2 or more consecutive hours in the first 12 postoperative hours, $84 \mathrm{~mL} / \mathrm{kg}$ or more total for the first 24

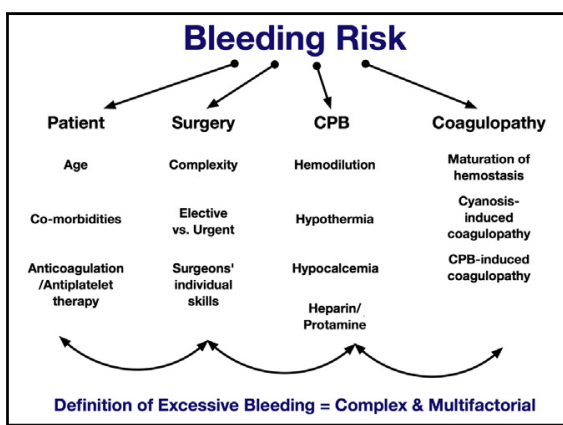

Factors associated with bleeding in neonates and children undergoing cardiac surgery.

Central Message

The current study confirms the large intercenter/study heterogeneity in terms of postoperative bleeding and supports the need for center-based definition of excessive bleeding.

See Article page 2112 .

postoperative hours, or surgical reexploration for bleeding or cardiac tamponade physiology in the first 24 postoperative hours. The definition of bleeding was then internally validated in a cohort of 77 infants and neonates.

The challenge when addressing excessive bleeding in congenital heart surgery comes from the significant

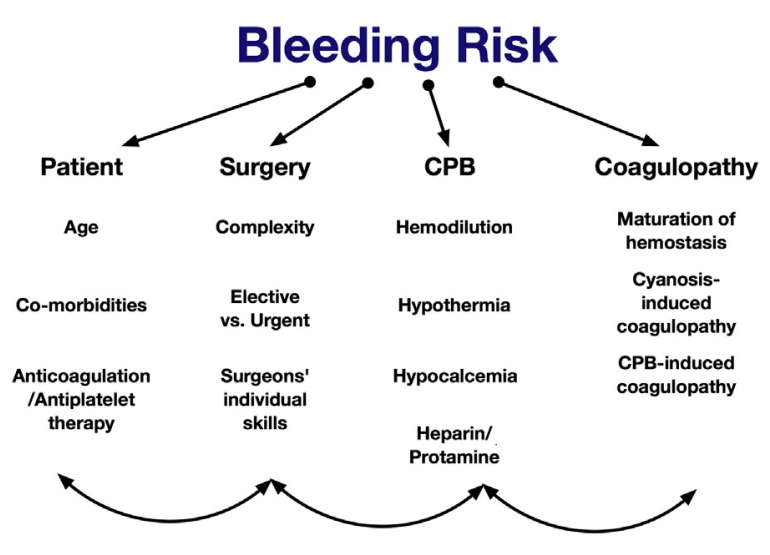

Definition of Excessive Bleeding = Complex \& Multifactorial

FIGURE 1. Factors associated with bleeding in neonates and children undergoing cardiac surgery with cardiopulmonary bypass. Patient-related factors, surgery-related factors, cardiopulmonary bypass-related factors, and the degree of coagulopathy itself. $C P B$, Cardiopulmonary bypass. 
heterogeneity between centers in terms of perioperative management, patients' comorbidities, surgical complexity, and surgeons' individual skills and experience. This major challenge is clearly highlighted by the authors, showing that the definition leading to a $24 \%$ incidence of excessive bleeding in one center leads to an incidence of $69.4 \%$ in the authors' center. Also, if the incidence of postbypass blood product transfusion is close to $0 \%$ to $5 \%$ in some centers, exposure to blood transfusion can reach $100 \%$ in other institutions. The large variability observed not only reflects the challenge of defining excessive bleeding in each center but also reflects the complexity of comparing centers with different perioperative management strategies, centers with different volumes and experience, and centers performing surgeries of different complexity.
The results of the study published by Bercovitz and colleagues ${ }^{4}$ confirm the large inter-center/study heterogeneity in terms of postoperative bleeding and support the need for center-based definition of excessive bleeding.

\section{References}

1. Guzzetta NA. Benefits and risks of red blood cell transfusion in pediatric patients undergoing cardiac surgery. Pediatr Anesth. 2011;21:504-11.

2. Cholette JM, Faraoni D, Goobie SM, Ferraris V, Hassan N. Patient blood management in pediatric cardiac surgery: a review. Anesth Analg. 2017;1.

3. Karimi M, Sullivan JM, Lerer T, Hronek C. National trends and variability in blood utilization in paediatric cardiac surgery. Interact Cardiovasc Thorac Surg. 2017; 24:938-43.

4. Bercovitz RS, Shewmake AC, Newman DK, Niebler RA, Scott JP, Stuth E, et al. Validation of a definition of excessive postoperative bleeding in infants undergoing cardiac surgery with cardiopulmonary bypass. J Thorac Cardiovasc Surg. 2018; 155:2112-24.e2. 